\title{
More nearly certain
}

\author{
Imogen Evans
}

J R Soc Med 2005;98:195-196

If you turn to the television comedy archive channel on your multimedia display system you should be able to locate a series of political satires called Yes Prime Minister. Created 20 years ago, they remain hugely popular today. Dear reader in 2055, I'd like to think their linguistic contortions are sufficiently timeless to make you laugh too. In one episode the PM, Jim Hacker, plans to cancel an order for a very expensive nuclear missile. Sir Humphrey Appleby, Civil Service supremo, tries to argue him out of it. The verbal exchange hinges on the concept of uncertainty on the part of those at whom the missile might be directed.

Appleby: 'It's a deterrent.'

Hacker: 'It's a bluff. I probably wouldn't use it.'

Appleby: 'Yes, but they don't know that you probably wouldn't.'

Hacker: 'They probably do.'

Appleby: 'Yes, they probably know that you probably wouldn't. But they can't certainly know.'

Hacker: 'They probably certainly know that I probably wouldn't.'

Appleby: 'Yes, but even though they probably certainly know that you probably wouldn't, they don't certainly know that, although you probably wouldn't, there's no probability that you certainly would.'

In everyday conversation one often hears the phrase 'we live in an uncertain world', or words to that effect. From its traditional roots, for example in the sphere of physical measurement, uncertainty has become pervasive. Environmental scientists struggle with it while trying to convince policy-makers about the dangers of greenhouse gases and global warming. Lifestyle therapists offer confidenceboosting services over the internet so that people can cope with it now and live with it in the future. And modern philosophers sit back and ponder how we got into this fix. After all, their 18th century Enlightenment forebears clearly envisaged that industrial civilization would lead to

Imogen Evans, MD PhD, is Clinical Research \& Ethics Liaison Manager at the Medical Research Council, London. In earlier life she was an honorary consultant endocrinologist at the Royal Postgraduate Medical School and Executive Editor, The Lancet.

Crug-las, Dinas Cross, Newport, Pembrokeshire SA42 OYH, Wales, UK

E-mail: critchlow.evans@virgin.net a vastly different conclusion, with the advance of science putting us in control of our destiny. ${ }^{1}$ If they had been right we should be living in an orderly, but probably rather boring, world as masters of our own fate.

Uncertainty has likewise become a hot topic in medicine. Yet, disquieting though this may seem, it is inseparable from progression of knowledge. The condition known as variant Creutzfeldt-Jakob disease (vCJD) is bounded by various medical uncertainties. This novel human prion disease, characterized by progressive ataxia, myoclonus, and ultimately dementia, first appeared in the UK round about 1995. It is currently fatal 9-35 months from diagnosis. Quite quickly, experimental evidence showed that vCJD was caused by the same prion strain as that involved in bovine spongiform encephalopathy (BSE or mad cow disease). Was there to be a major human epidemic, as with BSE in cattle, resulting from dietary or other exposure to BSE prions? So far, this has not happened: those affected seem to have had a particular genetic makeup, being homozygous for methionine at prion protein gene codon 129. Will there be a second and much larger wave of cases among heterozygotes? This is one of the uncertainties for us - you in 2055 must know the answer.

vCJD has also flagged up the issue of uncertainty surrounding the effects of treatments. Since very few treatments have startlingly obvious effects - the penicillin category-uncertainty will surround the effectiveness of most of them. While some of these uncertainties are trivial, others are very important and are reflected in striking variations in clinical practice. Today, a man with benign prostatic hypertrophy treated in one clinic will be prescribed drug treatment; a similar man attending another clinic will be advised to have surgery. For osteoarthritis of the hip, prosthesis A will be used in one hospital, prosthesis $\mathrm{B}$ in another. And so it goes on. As has been said of science, when the evidence is inconclusive the vacuum is filled with the assertion of contradictory certitudes. ${ }^{2}$

Most treatment effects will be modest rather than dramatic; carefully controlled tests are needed for unbiased assessment. But although randomized controlled trials in medicine have been conducted for more than 50 years, even today trials are done without the necessary safeguards against bias. Recently systematic reviews have been brought in to assess the accumulated results, clarify the evidence thus far, and define the need for new trials. And now 
researchers are being urged to register all new trials to make it quite clear what treatments are being tested and how, where and by whom. These are the research underpinnings for the evidence-based-medicine agenda, which should be second nature to you in 2055. And along with these developments we have seen the belated recognition by medical professionals that patients are an integral part of the research endeavour. In the case of CJD, researchers, with involvement of patient representatives, have begun a clinical trial of quinacrine, for which there is some evidence of activity in animal models. Perhaps you will look back on this with amazement; the disease has died out or is prevented by anti-prion immunization.

But one thing is for sure-you will still be facing uncertainties about the effects of your treatments, especially those that are newly introduced. ${ }^{3}$ So what should happen when, after weighing all the evidence about treatment options for a condition, uncertainty remains? Some doctors, not unreasonably, argue that the ability to make a judgment in the face of uncertainty defines the art of medicine and sets it apart from reductionist science. Today this art is practised in almost every clinical setting; perhaps your approach in 2055 is more mechanistic but I doubt it is wholly so. Yet whereas for us the need to address the issue of treatment uncertainties in a formal sense, and to discuss the options explicitly, has only lately arrived on the medical agenda, for you it should be part and parcel of medical practice.

So where are we with addressing uncertainties about the effects of treatments? The debate has only just begun but is already wide-ranging. Let me give you a flavour. Despite general acknowledgement that patients are partners in medical research and healthcare decisions, the complexity of discussing therapeutic uncertainty with patients is unnerving some doctors. Some are simply fearful of provoking anxiety - doubtless a genuine concern but nevertheless paternalistic. Others try to justify their actions in terms of a balance between two ethical arguments - whether the ethical duty to tell the truth extends to being explicit about uncertainties versus the moral obligation to protect patients from emotional burden. Are patients prepared to live with uncertainty? We need to find out. Perhaps people are far more resilient than doctors suspect: in the face of uncertainty concerning BSE-infected beef and $\mathrm{vCJD}$ we did not all become vegetarians. One woman undergoing mammographic screening for breast cancer has commented that she can live with her doctors expressing uncertainty but does not wish to live with dishonesty. ${ }^{4}$

In response to this there has been a call for clinicians to initiate a constructive debate with each other, with patients, and with the public. One approach to lessening uncertainty is to conduct more properly controlled clinical trials; as one ethicist has commented, in the face of uncertainty the trial is the treatment. ${ }^{5}$ And we know that such an approach can pay dividends. For example, as a result of the inclusion of virtually all childhood leukaemia patients in clinical trials, the improvements in treatment have made a striking difference in survival. Paediatric oncologists clearly expect that decisions about treatment should be taken within the context of controlled trials. The mystery is why other professional groups thus far have not followed suit. And efforts are now being made to encourage health service managers to recognize that addressing uncertainties is their business too. Their support is needed to foster clinical trials in hospitals as an integral part of the pattern of care and to question why individual doctors might choose to treat patients outwith a trial protocol if an approved one is available. $^{6}$

Dear reader in 2055, if you have succeeded in tackling these issues you will have lessened uncertainty about the merits of treatments, to the benefit of all. You will also have put uncertainty on the pedestal where it belongs - as an exciting and necessary stimulus to medical progress, to be exploited for its true worth, not feared. As the philosopher Bertrand Russell put it, you will have ensured that 'some things are more nearly certain than others'.

\section{REFERENCES}

1 Giddens A. 1999 Reith summary lecture for UK alumni [of the London School of Economics] (transcript) [www./lse.ac.uk/collections]. Accessed November 2004

2 Adams J. Risky Business: the Management of Risk and Uncertainty. London: Adam Smith Institute, 1999

3 Chalmers I. Well informed uncertainties about the effects of treatments: how should clinicians and patients respond? BMJ 2004;328:475-6

4 Palacios D. Re: Senators hear from experts. Then support mammography. New York Times, 4 March 2002:A20

5 Ashcroft R. Giving medicine a fair trial. BMJ 2000;320:1686

6 Chalmers I. Managers should help to address important uncertainties about the effects of treatments. BAMM News, June 2004:3-4 